\title{
Educating Future Energy Engineers for Sustainability: Case Study in Energy Economy
}

\author{
Şiir Kilkiş \\ Faculty of Sciences Energy Engineering Graduate Program, Başkent University, Ankara, Turkey \\ e-mail: siir@baskent.edu.tr
}

Cite as: Kilkiş, Ş., Educating Future Energy Engineers for Sustainability: Case Study in Energy Economy, J. sustain. dev. energy water environ. syst., 3(1), pp 26-48, 2015, DOI: http://dx.doi.org/10.13044/j.sdewes.2015.03.0003

\begin{abstract}
This paper analyzes the case study of an interdisciplinary course in Energy Economy that was developed at the Energy Engineering Graduate Program at Başkent University. The course integrated several unique pedagogical features to satisfy the aim of developing a working knowledge in energy economy with an energy systems perspective. The novel aspects of the course thematically led to a capstone research project where 5 teams of 17 course participants analyzed their prioritized solutions towards improving the energy self-sufficiency of the campus based on the practice of energy economy. The results of the teams' solutions towards a net-zero energy/exergy campus included electric buses for city-campus transport, poly-generation for the new Arts Center, LED/OLED lighting for campus lighting, dynamo driven/piezoelectric sports center, biofuels from the university-owned dairy products farm, and an energy efficient technology incubation center. This unique course with participatory learning is compared with others before concluding that the case study is a useful international example for energy economy.
\end{abstract}

\section{KEYWORDS}

Education, Energy economy, Engineering, Participatory learning, Sustainability, Net-zero energy campus.

\section{INTRODUCTION}

The development of human resources with the capacity of supporting sustainable energy systems of the future is a key challenge for society. This puts responsibility on higher education institutions to foster human resources who have an active awareness for producing innovative energy solutions for energy consuming sectors. For such reasons, Chen et al. argue that energy education should aim to foster insight on energy crises, the energy and environment nexus, and "holistic solutions" to ensure greater sustainability [1]. DeWaters et al. state that education for energy literacy should extend "content knowledge" to "citizenship understanding" [2]. Kandpal et al. emphasize the need to foster a sense of seeking solutions to civic problems and engage in activities that would lead to a sustainable society [3]. Similar arguments are made for engineering education in general [4-6]. Especially at a time when the "sixth wave" of innovation builds on such trends as radical resource productivity, including for energy resources, a whole of system approach for curriculum renewal is needed to foster human resources who can meet this challenge [7].

Beyond the "three roles" of providing education, conducting research, and fostering local engagement and entrepreneurship [8-10], this challenge requires that higher education institutions take on a "fourth" role for a sustainable society. Some universities, for example, have offered their campuses as an "open laboratory" for analyzing possible energy solutions. In the literature, studies that analyze energy solutions for campuses report both renewable and alternative energy solutions. Y1ldirım et al. describe a 
geothermal energy based district heating system for a university in Turkey [11]. Pagliarini et al. model a thermal energy storage system that is coupled with combined heat and power generation for a university campus in Italy [12]. Shang et al. analyze a scenario for the use of a hydrogen fuel cell hybrid scooter in a campus in the UK [13]. Spencer et al. design a combined heat and hydrogen plant for a campus in the US [14]. Spirovski et al. describe the process of preparing a Climate Action Plan towards the realization of a low emission campus in Macedonia [15]. These studies that propose campus energy solutions have been conducted independently of the academic curriculum without an organic link to the use of participatory approaches. On the other hand, Lo reports on the state of energy conservation in higher education institutions in China based on an examination of eight universities [16]. Zografakis et al. present inquiries into effective education models for energy efficiency in Greece [17]. Similar searches continue and clearly, there remains room for improvement.

Most recently, universities have presented campus action plans under the International Sustainable Campus Network (ISCN) Gulf Charter. A total of 56 universities around the world are signatory institutions to the Charter in which one of the aims is to create an open laboratory for sustainability [18]. The Charter states that facilities, research, and education should be linked to create a living laboratory for sustainability [18]. Some of the member universities of ISCN that are active in restructuring their campus energy systems include Lappeenranta University in Finland, which uses a smart grid system [19], and Chatham University in the US, which is planning to integrate solar arrays and geothermal energy next to energy saving measures [20]. On the other hand, the National University of Singapore (NUS) has relatively recently put forth a goal to increase the number of "courses that use participatory and project based teaching" [21]. It is stated that the "participatory method" should be used to stimulate and motivate students [21]. Even in ISCN members, there is limited integration of campus sustainability initiatives with the academic curricula.

A key premise of this paper is that a working knowledge of energy economy should be integrated with creative, interactive projects within the course content to reinforce the more active, engaged skills that are expected of an energy engineer for a sustainable $21^{\text {st }}$ century. In this respect, this paper analyzes the case study of an interdisciplinary course that was developed in Energy Economy within the Energy Engineering Graduate Program at Başkent University in Ankara, Turkey. The objective of the related Graduate Program is "to raise engineers who have an internalized knowledge of energy systems, can develop innovative strategies and long-term technologies, have an interdisciplinary and integrated approach to problems, can produce solution alternatives to discuss and select the most feasible decisions, are aware of the environmental and economic needs of the society, and are equipped with excellent research capabilities" [22]. The pedagogical features of the course were integrated with the aims of the Program to design and apply a novel course to foster energy engineers with a dedicated awareness on energy economy and its applications.

Despite the general concern in the literature towards the need to increase approaches in education that emphasize participatory learning, an approach to integrate the academic curriculum with the objective of posing the campus as an "open laboratory" for energy solutions has not been readily adopted in the literature to the best knowledge of the author. This integration required the development of a novel pedagogical methodology to foster an active understanding and awareness for allowing students to seek ways to increase energy economy in society while gaining the capacity to propose robust energy solutions. The proposition that a novel course design in Energy Economy can integrate participatory learning principles while presenting the campus as an open laboratory for energy solutions has been validated by the case study of this paper. In the analysis of the case study, the course in Energy Economy led to a research capstone project where 5 
teams of 17 course participants had the opportunity to analyze and prioritize their solutions towards improving the energy self-sufficiency of the campus.

\section{METHODOLOGY OF THE PEDAGOGICAL CASE STUDY}

The methodology of designing the case study in Energy Economy is grounded in an understanding of pedagogy as the "science and art of education" [23]. In the philosophy of pedagogy, an educator should provide not only the relevant knowledge but also foster skill-building in the students to allow them to attain complementary skills. Bloom's taxonomy seeks to motivate educators to consider a more holistic form of education beyond knowledge [24-26]. The taxonomy expands the domains of education into the six integrated aspects of knowledge, comprehension, application, analysis, synthesis, and evaluation [26]. This transforms the process of education into a more interactive medium, which includes discussion, problem-solving, imaging, comparing, and assessing.

In the literature, Bielefeldt analyzes the different pedagogical methods that have been used to educate civil and architectural engineering students about sustainability in one institution in the US [27]. Project-based learning (PBL) is used as one of the methods to reach the "synthesis level" of Bloom's taxonomy [27]. Case studies, project reports, and capstone design have also been given a role within the last three domains of the taxonomy [27]. Within the different courses in the department, examples of these and other methods include "clicker questions" to evoke discussion and active learning in students, 30 minute group-based activities, and the use of a Leadership in Energy and Environmental Design (LEED) platinum-rated dormitory as a case study [27]. Bielefeldt concludes that such methods can allow students to meet the learning objectives at a higher cognitive level. It is also found to underline the message that sustainability should always be considered in engineering for good design - it should become a "normalized" activity [27].

Jollands et al. analyze the role of PBL in chemical engineering courses in Australia [28]. Groups select an issue related to sustainability, research the issue, and present it to the class with weekly 30 minute meetings with the supervisor. The authors use a focus student group ( $N=11$ students) to discuss and reflect on the impacts of PBL, compare the breadth of about 60 Concept Maps that relate aspects of sustainability in brain-storming sessions, and analyze the results of a test before and after the provision of a sustainability module. As a favored method to develop graduate competencies, the authors find that PBL provides key advantages to increase the understanding of sustainability. The students report that PBL has changed their outlook towards the issue [28]. Other studies define such instances of learning as "epistemic learning" where students experience a paradigm shift in their outlook towards an issue [29], such as sustainability [30].

Disterheft et al. analyze participatory approaches in the context of the sustainability assessment reporting practices of universities [31]. The authors seek to fill the missing gap in assessing participatory approaches and their impact on more sustainable universities. The research design includes semi-structured expert interviews and focus group discussions with a total sample size of $N=51$ across 20 countries. The authors find that the success of such approaches is dependent on structural institutional conditions, the persons engaged, specific skills, and participatory competencies. Since Disterheft et al. focus on sustainability assessment in universities, the integration of participatory approaches within the academic curriculum is not addressed. This supports the fact that the integration of university campus sustainability and academic curricula is still lacking.

Especially in the $21^{\text {st }}$ century, education needs to be a wellspring to allow there to be a better practice of sustainability in society that flourishes with new ideas, applications, and systems. The decade up to the year 2014 has been declared as the "UN Decade for Education for Sustainable Development" [32]. However, there is still a long way to go to 
transform mainstream education to support more sustainable systems, including energy systems. In its aim, the pilot case study of this paper contributes to this greater effort.

\section{Research design and framework of the case study}

The exploratory case study of the present paper has been designed according to the key principles that are set-out by Yin [33]. Yin defines a case study as "an empirical enquiry that investigates a contemporary phenomenon in depth and within its real-life context" [33]. Among other aspects, this requires the definition of research design, linkage of results from data sources to propositions to validate/disprove the research questions, and criteria for interpreting the findings [33]. The sources of evidence are given to include documentation, interviews, direct observation, and/or participant observation. It is suggested that there should be multiple sources of data, including both qualitative and quantitative data, and there should be a chain of evidence. The process of pattern matching whereby the empirically based pattern is compared with a predicted one is also given as strengths in a case study as well as the ability to trace changes over time [33].

Considering these principles, Figure 1 sets-out the main framework of the case study in designing a participatory course in Energy Economy and applying it to a sample of 17 graduate students who enrolled in the course. The research questions are three-fold:

- Q1: How can a course in "Energy Economy" be designed to integrate learning objectives with an applied approach based on participatory learning?

- Q2: How can it foster skills that will empower future energy engineers to propose solutions and address challenges in society related to energy economy?

- Q3: What will be the impact of a course that integrates a participatory learning approach on achieving a high level of educational satisfaction?

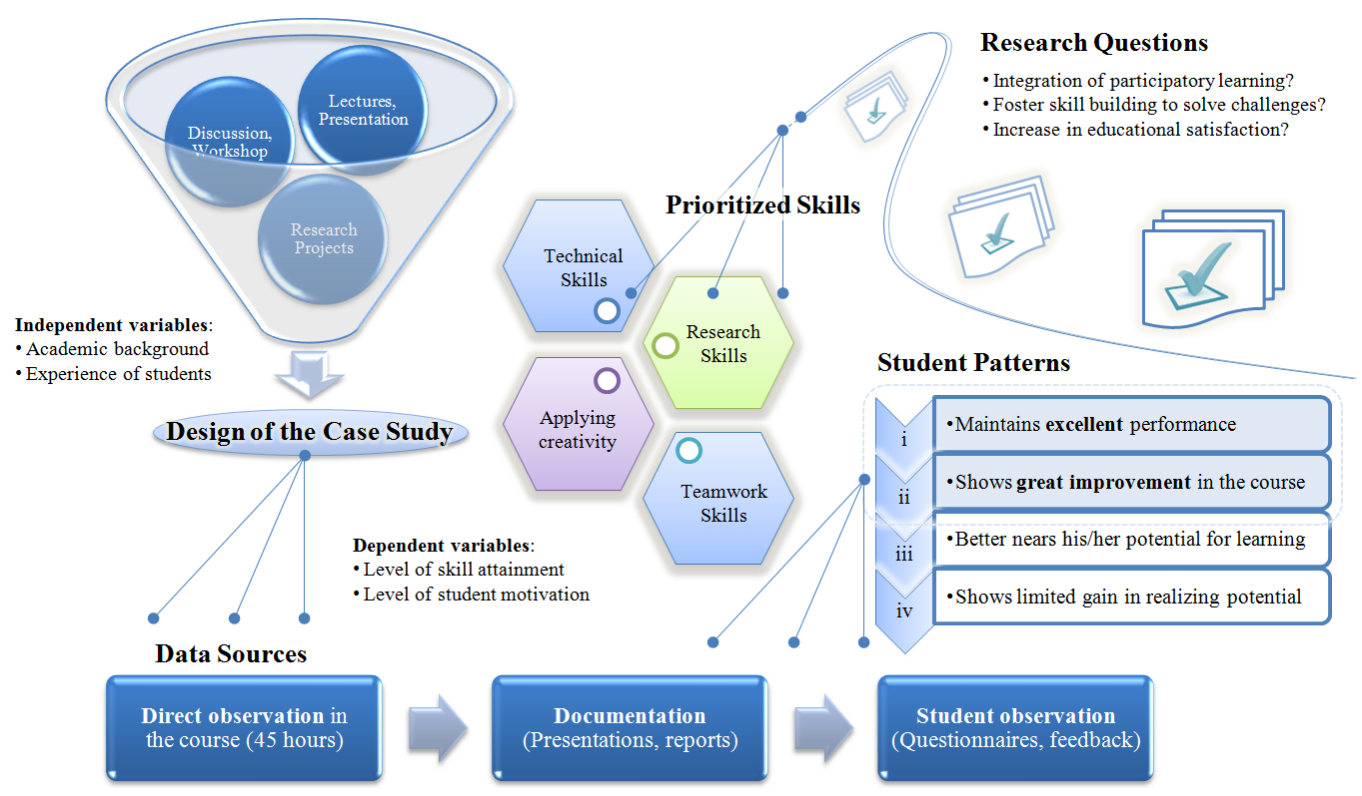

Figure 1. Main framework and research design of the case study

Based on the research questions, the planning of the course was structured based on an approach of participatory learning. The propositions for the research questions Q1-Q3 are centered on the expectation that such a pilot course can be designed and applied to the student sample to contribute in empowering these future energy engineers to begin 
addressing energy economy related challenges in society. In addition, it is expected that the design of the course will lead to a high level of educational satisfaction by the students. If successful, the course could become an example of good practice in other courses and for other universities in the world, especially those with an ambition to progress towards "sustainable universities." The course could be an example of coupling green campus targets with pedagogical aims, including other courses in energy economy.

While the details of the case study are given in the next section, the course content included instructor lectures, student presentations, discussions, a participatory workshop, and a capstone research project. The independent variables include the academic background and experience of the student sample. The students who are accepted into the Energy Engineering Graduate Program have a diverse range of undergraduate degrees. The majority of the 17 students in the sample who enrolled in the course had academic backgrounds of engineering (electrical, environmental, mechanical, and industrial engineering) with the minority being in the sciences (chemistry and physics). In this way, the student sample was largely representative of the students in the Graduate Program. In addition, about $55 \%$ of the students had work experience in the government sector (Ministry and affiliated institutions, a municipality), the engineering sector (various firms in the sector), and other sites (industrial zone management, a public hospital).

By design of the case study, the course content is expected to increase a set of prioritized skills, including intellectual and cognitive skills for technical and research related activities in energy economy. In addition, these skills are to be integrated with a supportive set of skills, including teamwork, leadership, and the ability to apply knowledge-based creativity to solve and/or address challenges in energy economy. All of these skills may be seen to correspond to the domains in Bloom's taxonomy following those of knowledge and comprehension, including application, analysis, and synthesis.

The variables that are dependent on the pedagogical structure and features of the case study are the levels of skill attainment in the students and the level of student motivation towards the course. Depending on the success of the design of the course, it is possible to expect the patterns of student progress to be in four possible main pathways. These are students who maintain excellent performance in the course from start to end (pattern $i$ ), students who show great improvement during the course (pattern ii), students who are able to better near his/her potential (pattern iii), and students who show limited gain in realizing their performance potential in the course (pattern $i v$ ). It is a general aim to maximize instances of student patterns $i$ and $i i$ while minimizing instances of student patterns $i i i$ and $i v$. In addition to meeting content-related milestones, a key pedagogical merit of any course is based on the ability to encourage all students to better utilize their potential in excelling to meet the course objectives. In addition, the instructor should recognize instances of pattern $i i i$ or $i v$, if any, and intervene to change these patterns.

The case study was analyzed based on the inputs of multiple data sources (see lower part of Figure 1). The data sources included direct observations by the instructor for a total of 14 lectures plus the final session in which students had the opportunity to share their capstone research projects. In total, there were 45 (in-class) hours that were available to directly observe the understanding, engagement, and performance level of the students in response to the design of the course content. A second source of data input included the documentations that were prepared by the students. These included presentations and research reports either prepared individually or in teams. These inputs further increased the depth of direct observation since it enabled additional mediums to observe, question, and assess student progress outside of in-class hours. The third data source is based on inputs from participant (student) observations. This included questionnaires given by the instructor at the beginning and end of the course, feedback by 
the students during the course, and the formal course evaluation. As highlighted within Figure 1, the course was successful in allowing all students to follow patterns $i$ and $i i$.

\section{DESCRIPTION OF THE CASE STUDY IN ENERGY ECONOMY}

The case study in Energy Economy integrated several unique pedagogical features to satisfy the aim of developing a working knowledge in energy economy for all students in the sample $(N=17)$. In the aspect of intellectual and technical skills, the course fostered knowledge-based skills to generate efficient solutions within an energy systems perspective. This further included an understanding of the "quality" of energy resources (exergy) that were reinforced by the course content that was novel in design. Second, the practice of weekly "Energy Agendas," which involved collective effort and leadership, integrated the course content with contemporary issues. This may be seen to be forms of "active learning" where the students presented and posed discussion questions to their fellow students. Third, the course involved an interactive, collaborative workshop in which statistics on the energy usage of the campus were presented for teams to generate and rank their solutions to reduce energy consumption and increase local energy production on campus. This has been designed as a unique capstone research project.

Figure 2 provides a stepwise summary of the pedagogical features of the case study of this paper starting from the toolkit for an energy systems perspective leading to the campus application in the capstone project. The knowledge and skills that each of the pedagogical features are designed to provide to the students are briefly indicated next to each of the features, e.g. metrics for feasible energy solutions to scenario-building and analyzing ideas. The details of these pedagogical features are described in turn below.

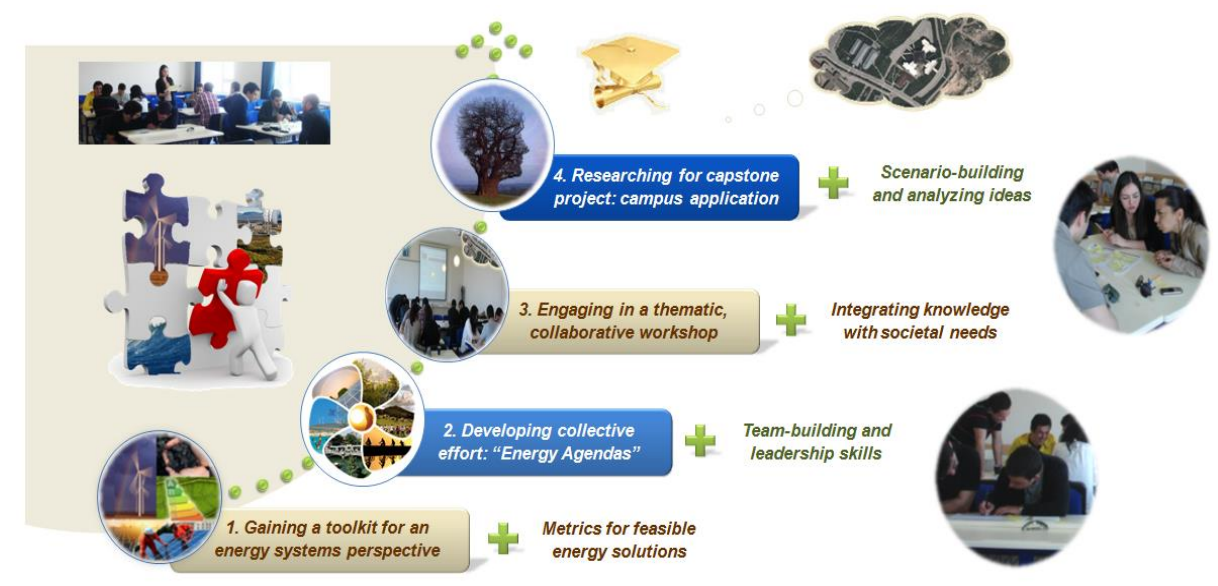

Figure 2. Stepwise summary of the pedagogical features of the course

\section{Gaining a toolkit for an energy systems perspective}

Beyond other courses in energy economy, a novel aspect of the course was the emphasis that was placed on "energy economy" as a vital "key" to ensuring a more rational usage of energy resources and solving the energy challenges of society. As a result, a "toolkit" of metrics and indicators were provided in the first part of the course. By applying the metrics in the toolkit, the students would be able to use a working knowledge of energy economy as their solution partner in designing and proposing solutions to various levels of energy challenges in later projects. From the beginning, it was emphasized that as energy engineers, each student must have the vision to apply this toolkit to various levels, which may range from an equipment sizing level to the building level, and even to the campus and district level. This broader outlook that encompasses 
the entire energy system is also fitting with the objectives of the Graduate Program in Energy Engineering, which seeks to raise researchers who have a wide and integrated vision of the energy system as a whole.

Sample indicators from the toolkit. In the case study, the main toolkit is developed to include a set of about 25 indicators, metrics, and evaluation methods. It was introduced after a basic overview of energy statistics, such as primary energy supply, total demand, and final energy consumption. This made it possible to emphasize that society may more frequently question "how much energy is used" but may not question enough "how rationally do we use the energy?" This sequence directly placed the toolkit in the context of aiding to answer one of the most pressing questions in society: "how can we use energy more rationally and efficiently?" In answering this question, the toolkit was introduced in three distinct groups.

First, indicators and metrics that are able to give an understanding of the efficiency with which energy resources are used, such as conversion, distribution, and transmission efficiencies, were introduced. In so doing, it was emphasized that it is not sufficient to look at only "efficiency" at the end-user side. The entire energy supply chain from the production of energy resources to the end user must be considered. Furthermore, the Rational Exergy Management Efficiency was introduced as a model to assess how well the quality/grade (exergy) of energy resources are matched to the quality/grade of demands [34]. In fact, this greater concern on how well energy resources are allocated to matching demands in the energy system from an exergy point of view was taken as one of the central concerns for energy economy. This affects many aspects from primary energy spending to compound $\mathrm{CO}_{2}$ emissions [34]. One of the last indicators in this group included the power to heat (alpha) ratio that is particularly relevant for Combined Heat and Power (CHP) systems.

It was beneficial to introduce the second group of metrics as metrics that take a total value that is relevant for energy economy and represent it for one unit (per unit). This group involved the amount of energy $\mathrm{kWh}$ for one squared meter $\left(\mathrm{m}^{2}\right)$ per year that is widely used in regulatory documents, such as the Energy Efficiency Directive [35] and the Building Energy Performance Directive in Turkey [36]. It further included other measures for transport, such as the number of litres per $100 \mathrm{~km}$ that is useful to compare the range of hybrid and electric vehicles. Energy consumption per passenger kilometre was introduced to compare different transport options, including aviation, subways, metro, and commercial vehicles. The amount of $\mathrm{CO}_{2}$ emissions per one $\mathrm{kWh}$, which is useful to compare the energy content of energy resources, such as household waste, biofuel, and natural gas, was another metric. It was emphasized that indicators should be diversified as much as possible to be able to see the entire energy picture. This included the classic indicators for energy economy, such as cost per unit of energy, etc. Feed-in tariffs that give a subsidy per each unit $\mathrm{kWh}$ generated is another metric within this group of metrics.

The reason that metrics, such as payback period, were put inside the last group was due to the reason that in reality, payback period is dependent on the other two groups of indicators. For example, the more energy that is saved by a system due to more efficient design, etc. means that there will be a shorter amount of time for a system to return the initial investment, given a fixed cost for the initial investment. This principle was demonstrated for various active and passive measures for buildings. It was also demonstrated for different generations of technology, including photovoltaic panels (e.g. silicon and dye-sensitized solar cells) and different models of hybrid vehicles. The effect of the rising costs of fossil fuels on shortening the payback period of energy saving 
measures was another exercise. The factor of learning curves in technological progress was also introduced to indicate how the unit costs for initial investment are dependent on industrial learning and production amounts [37]. Therefore, it was advised that in comparison to the previous two groups, the third group is dependent on numerous other techno-socio-economic factors.

From the start, the method of distinguishing different groups of metrics within the toolkit was useful throughout the course, and in particular, in referencing the need to use more than one kind of indicator to be able to decide the more feasible energy solutions. The different assignments that were given in the course also had the criteria of using more than one group of indicator. This included "Technology Summaries" to compare the energy economy of different energy technologies with multi-criteria assessments (for example, the efficiency and cost of the different generations of photovoltaic technology). In all tasks, an emphasis was put on the ability to compare, contrast, and discuss issues of energy economy.

\section{Developing collective effort: "Energy Agendas"}

By pedagogical design, the technical content of the course was complemented by activities that develop team-building and leadership skills. One of the most fruitful of these activities was the weekly "Energy Agendas." Since energy economy is so vital for society yet it may often be overshadowed next to political headlines, it was decided that each course should start with "Energy Agendas" to be able to place emphasis on the priority that energy economy should be given. As a result, each course "opened" with a summary of current news from that week that involved energy economy. In the team-building and leadership aspect of this activity, fellow students were assigned as "reporters of the week" during which everyone else in the course would find and send one national and one international news to the reporter for that week. It was the responsibility of the reporter to present the news that was collected by the fellow students in an organized manner, finding common themes and logical groupings for the news. As a whole-of-class exercise, "Energy Agendas" had the roles of fostering active learning within the course, stimulating discussion, making observations, applying knowledge to analyze recent developments, and enhancing the linkage of the course with the real-world through the collective effort of the students.

Creativity in the presentation of "Energy Agendas" was another aspect that was incentivized in the course. For example, some of the reporters used more lively ways of presentation, such as the cloud based presentation software Prezi. As a result, the practise of opening each new course with a new energy agenda for that week provided a dynamic flow and discussion of current news into the course as well as a practise of public speaking for engineering students, which can be a skill that is more open for improvement in contrast to more social sciences based fields of study.

Distribution of the topics of energy agendas. In total, 112 different news topics were shared in the "Energy Agendas" that involved aspects of energy economy. Of this total, 65 came from national and 47 came from international news sources. These included such topics as the price hikes in natural gas and liquid fuels, gas and petrol reserves, shale gas reserves, new coal production methods, new solar energy applications for the future, artificial leaf technology, solar collector fields, and solar tower plants. It further included incentives for energy $\mathrm{R} \& \mathrm{D}$, green buildings and their effect on improving the national trade deficit, electric markets and electricity prices, electricity production from waste, bioenergy from seaweed, credits for energy efficiency, electricity production from drifts in the Bosporus, referendum for nuclear energy, and low velocity wind turbines. It was 
interesting that such a broad base of news involving energy economy was brought into the course with each one receiving an enthusiastic debate from the students. The most popular news topics in the course were the rise in electricity prices and new solar energy applications in Turkey. A collective view of all news in the energy agendas at the end of the course also provided a kind of "frequency analysis" in seeing the hot topics for the semester.

\section{Engaging in a thematic, collaborative workshop}

The various lectures of the course focused on a wide range of questions that spanned discussions on the results of different metrics, (e.g. the paradox of high energy efficiency and low exergy efficiency for boilers), the need for sustainable development with a concern for energy economy, the effect of the more rational use of energy resources on both the energy and trade deficit or surplus of different countries, and a survey of policies to improve energy economy (e.g. energy credits, incentives, and R\&D policies). Such a diversity of discussions enabled the students to better place the importance of developing solutions for improving energy economy into their daily lives because it was emphasized that "an energy engineer is always an energy engineer, whether driving to the university, waiting for a bus, or walking on the street." In this respect, an energy engineer requires a working knowledge of all metrics that are useful in improving energy economy. The mind of an energy engineer is constantly seeking possibilities to develop solutions for the energy needs around them.

This thematic design to the course led to a collaborative workshop in which the students were provided with energy statistics of the campus buildings and transport shuttles. This was based on the personal research of the course lecturer in order to make such a workshop possible. The pedagogical reasoning behind the workshop was the need to activate the students in applying their intellectual skills and the technical content of the course in developing solutions for their common living and working space - their own university campus. The inputs into the workshop session were supported by images of the campus area from Google Earth to provide a spatial dimension to the energy data. The data inputs, design, and results of the workshop are described in turn below.

Data inputs into the workshop session. The campus of Başkent University has twelve main types of buildings. These include the Office of the Rector and buildings for the five main Faculties, namely Education, Fine Arts and Architecture, Science, Literature and Engineering, Medicine, Dentistry and Health Sciences, as well as Law, Communication, Economic and Administrative Sciences. The buildings of the campus also include those for the State Conservatory, the new Concert Hall and Library (currently being built), and the university's public broadcast station, Kanal B. Finally, there are the dorm buildings, sports center, and buildings for other amenities. For each building, their heating loads, cooling loads (if any), steam loads (the washing rooms), natural gas consumption and electricity consumption were tabulated from all available data (energy bills, building surface area etc.). In total, the university buildings were found to have a heating load of 16.2 GWh, a cooling load of $5.9 \mathrm{GWh}$, and a steam load of about $1.6 \mathrm{GWh}$ on an annual basis. All loads were met with the purchase of natural gas at 2.8 million $\mathrm{m}^{3}$ and electricity from the national grid at $2.3 \mathrm{GWh}$ per year [38]. A comparison of the energy data for the building of the Faculty of Science, Literature and Engineering before and after its insulation project was further given.

In addition, the transportation program for the shuttles that run between the university and 31 different first stops in the various districts of Ankara were used to obtain basic data for transport related energy calculations. This included the number of shuttles per 
day to each first stop and the distance of these stops from the university. Further calculations were left to any scenarios that the students may conceive from these data (e.g. energy savings in buildings, alternatives, etc.). Figure 3 gives samples of the presentation that was used to open the workshop and its sessions as well as pictures from the workshop. The students as the workshop participants were encouraged to come up with innovative ideas to improve the energy economy of their campus through applying their knowledge from the course.

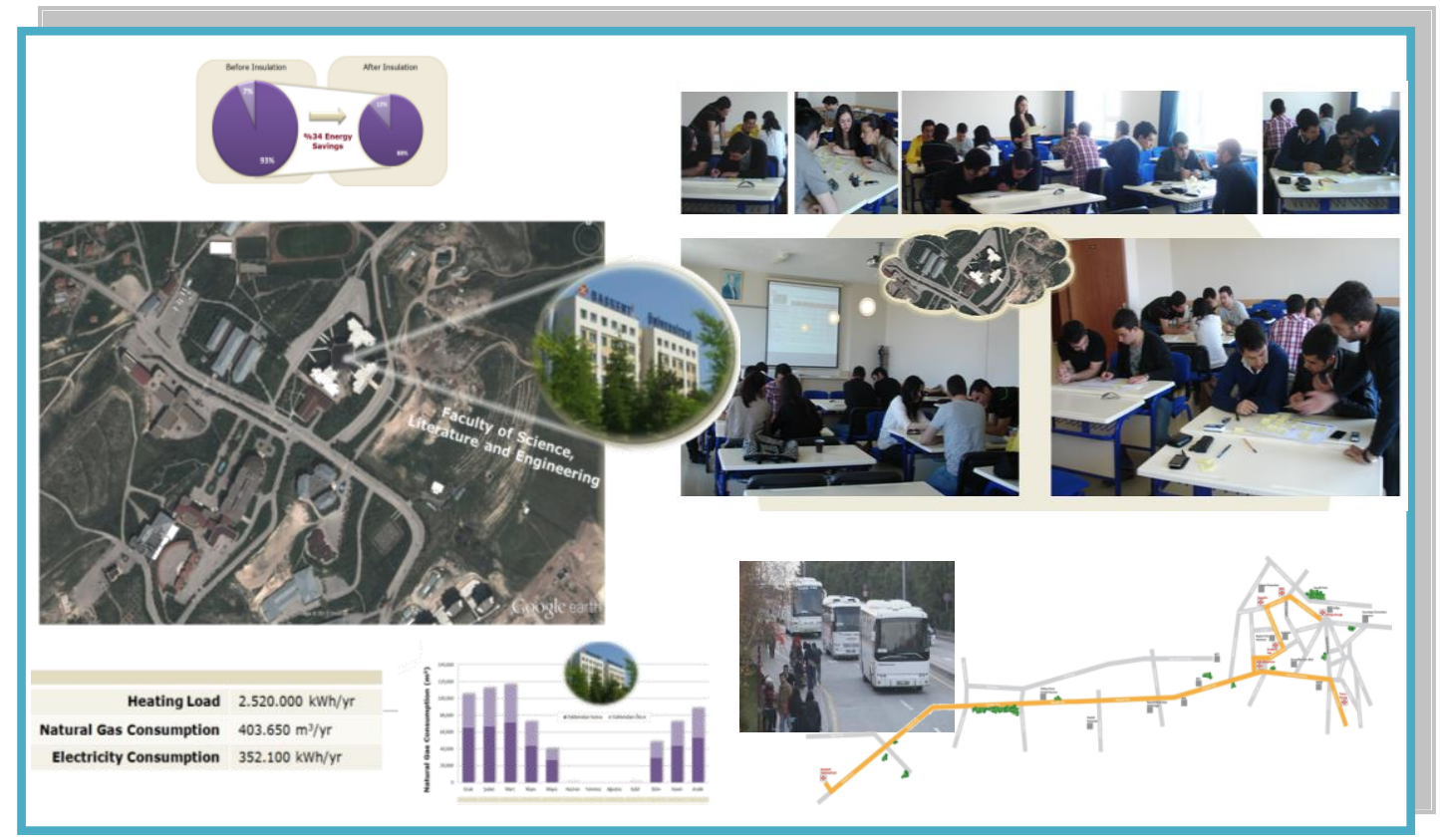

Figure 3. Sample presentation of campus energy profile (left) and workshop sessions (right)

Design of the workshop session and tasks. The workshop was designed to consist of three tasks, the first of which was a brainstorming session in which everyone wrote as many ideas as possible to improve the energy economy of the campus on a post-it and placed it on a matrix printed on A4 sized paper. The matrix was organized into four quadrants; the right quadrants being reserved for ideas that will increase the efficient production of energy on campus and the left quadrants being reserved for ideas that will reduce the energy loads of the campus. The top quadrants and bottom quadrants were reserved for categorizing these ideas into whether it involved high or low exergy measures. Each course participant was guided to come up with innovative ideas that can potentially fit in any one of the four quadrants. If it was seen that ideas piled up in one quadrant but not the other, then the team members were encouraged to consider ideas that can fill the other quadrants for more wholesome solutions. Discussion was further encouraged to produce synergy in generating new ideas. In total, the 17 course participants formed 5 teams.

After the brainstorming session, everyone was provided with votes to be able to rank the most popular 5 ideas of their team that they would suggest for further development. Based on the selections, the teams were asked to collectively fill another A4 chart with notes for justifying their selection. This included the importance of the idea for the more rational use of energy, the method that could be used to evaluate the feasibility of the idea (parametric calculations, considerations for scenarios to pre-test the idea etc.), and steps to carry out for future research. In essence, the A4 charts provided the first outline for the following final capstone project. In the third task, each of the 5 teams shared their results 
and views with the other teams. As a result, each team received feedback from the other 4 teams and the lecturer for their project.

\section{Researching the capstone project: campus application}

The major pedagogical objective of the course was to empower students to have a dynamic and working knowledge of energy economy so that they will be fluent in researching a topic of their own choosing with an in-depth analysis. It was emphasized that all knowledge is constantly changing, including energy economy. What is important in a "knowledge economy" is the ability to renew and make connections between existing and new information. With this objective in mind, the capstone project of the course was designed to be a continuation of the workshop so that each student would be responsible for fully researching at least one idea of their team. In this respect, the best ideas of the team should be developed and supported by research (efficiency, costs, etc.) and quantitative scenarios that can indicate whether the idea can be beneficial in improving the energy economy of the campus in reality (potential energy and cost savings, etc). Beyond individual responsibilities for research, each team was further asked to make a collective assessment on how the mix of ideas of their team would contribute to allow the campus to near a "net-zero" target if such a target should be put in the future.

Further inputs into the capstone project. During the three weeks that were given for research towards completing the capstone project, the lectures focused on specific applications that could benefit the students in giving examples of further analysis and scenario-building. One of these applications was the assessment of the Faculty of Science, Literature and Engineering Building, which underwent a comprehensive insulation project before the beginning of the academic year. This building was assessed from the perspective of the Building Energy Performance Directive in Turkey [36]. According to the Directive, the 81 provinces of Turkey are classified into four climatic zones. Reference values for different kinds of buildings are provided for each zone. For example, an educational service building in Ankara (with about 2,709 heating degree days in 2011 [39]) is considered to be in the third climate zone and is given a reference value of 300 $\mathrm{kWh} / \mathrm{m}^{2}$ per year [36]. This value is given to include the energy that is produced from the natural gas for heating and the energy that is spent for the electric energy that is used in the building, including conversion losses at the plant as well as distribution and transmission losses. While this is defined as the "primary energy supply" to the building by the Directive, it is in fact evaluated to be a quasi-definition since the total natural gas supply to the building is not considered.

In the Directive, the classes of $\mathrm{A}, \mathrm{B}, \mathrm{C}, \mathrm{D}, \mathrm{E}, \mathrm{F}$ and $\mathrm{G}$ are given to a building according to the savings that a building makes relative to the reference building. For example, a building is in the $\mathrm{C}$ category if its value is between a factor of one and only 0.8 of the reference value. To be in the category of $\mathrm{B}$ or $\mathrm{A}$, the building must have a value of at best 0.4 or less than 0.4 of the reference value, respectively. Since the reference value is given to be the primary energy spending, values for the heating loads, natural gas consumption, and electricity spending were subjugated to relevant factors to obtain their equivalent primary energy values (e.g. the calorific value of natural gas, average conversion efficiency of the boiler, average efficiency in the electricity grid from the plant to the end-user, etc). This exercise further assisted in developing the energy system perspective of the course based on an overall understanding of the energy value chain.

Based on two methods to obtain the primary energy supply to the Faculty of Science, Literature and Engineering Building, the building was in the D class prior to the insulation project and has neared the A class, falling in the B class with a $21 \%$ energy 
saving after the insulation project. More specifically, the building, which has a floor surface area of $20,673 \mathrm{~m}^{2}$, had a primary energy supply per $\mathrm{m}^{2}$ of $302 \mathrm{kWh} / \mathrm{m}^{2}$ (using heating load and electricity consumption data) or $303 \mathrm{kWh} / \mathrm{m}^{2}$ (using the natural gas and electricity consumption data) prior to the insulation project. After insulation, the building was found to have a primary energy supply of $237 \mathrm{kWh} / \mathrm{m}^{2}$, which represented an improvement factor of 0.79 against the reference value. An improvement factor between 0.4 and 0.8 is needed for a building in the B class.

Other sample inputs into the capstone project included an analysis of the same building based on the greenhouse gas emission classes of the Directive based on the final energy consumption, the electric energy that can be produced from sample daily wind energy readings at the campus, and lessons from other green buildings in Ankara, such as the OSTIM Green Building of the OSTIM Industrial Zone and the ESER Building, which is the first and only building to receive LEED Platinum in Turkey. In the time dimension, these were useful in paralleling the research efforts being conducted by the students.

\section{CONCEPTUALIZATION OF THE CAPSTONE RESEARCH PROJECT}

By definition, a campus is "net-zero" when the energy consumption of the campus is equated to energy production on an annual basis. From an exergy point of view [34], this definition may be extended to a "Net-Zero Exergy Campus" (NZEXC). A campus is a NZEXC when the annual amounts of energy consumption and production are equated on an exergy basis [38]. While the campus of Başkent University is currently dependent on the purchase of natural gas and electricity from the national grid, the challenge that the students of energy economy were given was to conceptualize the contribution of their ideas to such a target for the campus. As already identified in the workshop, each idea has the potential to increase the efficient production of energy and/or reduce the energy loads of the campus, both of which would contribute to a net-zero energy or exergy target. The exact nature of the potential contribution of the idea to improving the energy economy of the campus was explored within the capstone project. While open to creativity, a basic criterion for the research was to construct and analyze scenarios using at least four of the metrics in the toolkit introduced in the course. Related international best practises, if any, and a literature review were further required.

The solutions of the team towards a net-zero energy/exergy campus included electric buses for city-campus transport, poly-generation for the new Concert Hall and Library, LED/OLED lighting for campus lighting, dynamo driven/piezoelectric sports center equipment, biofuels from the university-owned dairy products farm, and an energy efficient technology incubation center. The main scope of the solutions as well as the pedagogical guidance that are given to the students are summarized below.

\section{Electric/hybrid buses for city-campus transport}

The idea for integrating electric buses in the fleet of vehicles for transporting students and faculty to and from the campus, located about $25 \mathrm{~km}$ outside of the city center, was an idea that was researched by 2 students from 2 different teams. In conducting their research, the students were advised to look into the motor efficiency, investment cost, and payback of electric vehicles. At the same time, the students were advised to consider that electric vehicles are not "zero emissions" as they are advertised, which can only be true for tailpipe emissions but not the emissions in the energy system as a whole. As a result, they were asked to conduct their scenarios also taking into account the primary energy supply from the power plants and the $\mathrm{CO}_{2}$ emissions of the energy mix of Turkey.

The two students made different scenarios, one also comparing the use of plug-in hybrid electric vehicles over purely electric vehicles. The transportation program as 
provided in the Workshop was also used to construct a base case scenario by multiplying the total distance with the fuel economy of the present shuttle fleet. The running costs of the present shuttle fleet and proposed fleet of electric vehicles were compared. The need to consider charging stations for electric vehicles was also emphasized.

\section{Poly-generation for the new Concert hall and Library}

In the overview that was given in the Workshop, the new Concert Hall and Library Building that was at the planning stage at that time was indicated to have an annual natural gas consumption at $256,000 \mathrm{~m}^{3}$ and an electric consumption of $485 \mathrm{MWh}$. The natural gas would be used to satisfy the annual heating load of $1.6 \mathrm{GWh}$ and the electricity would be used to satisfy the annual cooling load of $1.8 \mathrm{GWh}$ and all lighting needs of the building. The reason that this building would represent about $9 \%$ of the total natural gas consumption and about $21 \%$ of the total electric consumption of the campus was related to the heavy cooling and lighting needs of the Concert Hall and Library.

As a result, one idea that was considered was to include a poly-generation ${ }^{1}$ unit in the equipment room of the building that could utilize the incoming natural gas to satisfy a certain percentage of the heating, cooling, and electric loads. This required the student to research the energy economy of poly-generation technology. The student was further advised to compare the Rational Exergy Management Efficiency and $\mathrm{CO}_{2}$ emissions of a scenario with a boiler unit and scenarios with the proposed poly-generation.

\section{LED/OLED lighting armatures for campus lighting}

The replacement of fluorescent lighting armatures with more efficient LED/OLED lighting was explored by 3 students for 3 different contexts. One student focused on satisfying the lighting needs of the Faculty of Science, Literature and Engineering Building with LED/OLED armatures. Interestingly enough, this building would have higher electricity consumption after the insulation due to the use of tinted, double glazed windows in the classrooms. As a result, the possibility to use natural daylighting was reduced and the need to turn-on the fluorescent tubes in the classrooms had increased. The method that the student developed to construct a base case and alternative scenarios was based on a count of the number of regular lighting armatures in each classroom and multiplying this number for each classroom in a wing in one floor and all wings on all floors of the building. The luminous efficacy of radiation $(\mathrm{lm} / \mathrm{W})$ for fluorescent lighting and LED lighting was related to energy economy and the possibility of reducing the number of lighting armatures in the building. Beyond energy economy, the benefits of LED lighting on eye health were also investigated in the belief that solutions should consider multiple dimensions.

Another solution that involved the replacement of regular lighting armatures to LED lighting was for the lighting of roads, sidewalks, and the environment for campus safety. According to the distribution of electricity consumption across the campus, this category had an annual electricity consumption of $30 \mathrm{MWh}_{\mathrm{el}}$, which represented about $1 \%$ of the total electricity consumption. In addition, due to the heavy traffic load in the university entrance, especially in the mornings and evenings, a new road leading to the university was in the planning stage. Therefore, additional lighting would be needed for this new road that would increase the electricity consumption of the campus. The 2 different solutions that explored related ideas were the replacement of regular street lighting armatures with PV-supported LED lighting (retrofit of existing street lighting) and the

\footnotetext{
${ }^{1}$ In addition to the electricity and heat production in co-generation, poly-generation also produces a third output as cold based on absorption chillers. It is one of the multi-source multi-product technologies.
} 
inclusion of PV-supported LED lighting in the lighting of the new road. In their calculations, the students were advised to include the different night-time lighting durations for the summer and winter, which would also affect the insolation values. As a result, there would still be the need to purchase grid electricity, although at a lower amount due to the support of PV units.

\section{Dynamo driven equipment/piezoelectric locations on campus}

One student had the idea of integrating dynamos to the bicycle sports equipment in the sports center of the campus for the full and/or partial charge of iPhones and other small electric devices, such as mp3 players, while exercising. An international example at a sports center in Oregon was studied in order to make a system design recommendation. According to this, the student decided that simple dynamos could be retrofitted to the sports equipment but it would also necessitate a system for electric storage from which iPhones and other devices could be charged if not done in real time. The number of bicycle sports equipment, the dynamo efficiency, and the total number of hours spent by students in the sports center were considered to be limiting factors for the amount of electricity that could be generated with this solution. Another student had the idea of integrating this solution with other piezoelectric driven locations on the campus, such as hallways with heavy student traffic, car bumps, etc. The running band of the sports equipment was also another possibility to produce electricity. The motivation for these ideas was to capture the kinetic energy of daily movements for the possible generation of electricity. It was also observed that energy harvesting technology had rising market share [40].

\section{Biofuel from the university-owned dairy products farm}

A unique opportunity for the campus to replace some of its purchased energy (natural gas and electricity) through the possibility of producing its own energy comes from the university-owned dairy products farm that houses about 5,000 cows. As a result, this opportunity was turned into an idea of producing biofuel from the manure of the cows and the dairy waste of the facility. However, since the dairy products farm is located about $40 \mathrm{~km}$ away from the campus, it was advised that the idea also considers the logistic dimension of using the biofuel. In this respect, the option of using the biofuel directly for the energy needs of the campus was compared to the option of using the biofuel on-site at the dairy farm for the heating and/or electricity needs of the facility. The possibility that the campus could receive "green energy credits" for the biofuel that was generated at the dairy products farm was further discussed. The investment cost for the anaerobic digestion unit to produce biofuels was compared to the avoided costs of natural gas and electricity purchase from the grid due to the use of biofuels. Another alternative was the production of biofuel from cooking oils used within the campus.

\section{Energy management to purchase lower cost electricity at night}

Since the campus contains food areas, dormitories, and health facilities, the university has a washing load that cannot be overlooked. For this reason, high-temperature steam is produced from natural gas to satisfy the washing needs, which is estimated at $1.6 \mathrm{GWh}$ per year. An idea was to switch part of the washing equipment for pieces of cloth that need to be washed and do not require high-temperature steam to washers with at least an energy efficiency label of A+ and to purchase the electricity in the late night-time when it is cheaper. As in the case of the electric vehicles, the need to consider the primary supply of the electricity that would be used in the more efficient washers was emphasized for a broader energy systems perspective. 


\section{A funicular (cable car) system to complement public transport}

Another idea to overcome the consumption of fossil fuels to transport the students to and from the university campus was to construct a cable car station at the university entrance that has a steep, inclined plane. It was also discussed that not all students use the shuttles to come to the campus and the use of a cable car could offset the use of personal cars if it was sufficiently located near other public transport options. For example, for more than 15 years, the southern half of Ankara has been waiting for a metro line that could also benefit the traffic of the main highway next to the university. Therefore, the idea was to construct a cable car station below the inclined plane coming to the university next to the highway to receive students who could either park their cars below (creating a possible "no-car zone" in the university) or students who could use the metro if it is possibly completed in the near future. Since cable car systems use a counterweight principle, it was calculated that this option would use minimal electricity. It was discussed that this option could potentially conflict with the need to build a new road.

\section{Renewable energy for an energy efficient technology incubation center}

One student had the unique opportunity of bringing in experience from her workplace in an industrial zone that houses the OSTIM Green Building in Ankara. This idea explored the possibility of using alternative energy to satisfy the reduced loads of a potential energy efficiency technology incubation center at the campus. In Turkey, the inclusion of technology incubation centers and technology transfer offices at universities is encouraged as a means of increasing university-industry collaboration. While it was not known at the time that such a center could be opened at the campus, it was advised that such an idea could be explored for the future. Therefore, the options of using biofuels and hybrid combinations of solar/wind energy that may better steady-out the intermittent nature of either source when used singly due to variances in the peak solar and wind energy times of the day was explored with theoretical energy loads of a potential incubation center. Due to the intensity of the research needed to fully recommend what an ideal incubation center should be like, this idea was limited to the use of renewable energy sources at a potential incubation center.

\section{Outcomes of the capstone research project}

The above set of measures to improve the energy economy of the campus represents a diverse spectrum of ideas from those that can more easily be integrated into the daily student life of the campus, such as dynamo driven sports equipment, to those that would need approval of the university Senate, such as the instalment of a poly-generation unit in the new Concert Hall and Library Building. In addition, there are those measures in between, such as the option of integrating PV-supported LED/OLED lighting armatures on campus. Whether the ideas are small-scale or large-scale in nature, the students were encouraged that their ideas and their research represent a very valuable portfolio for the campus to consider. Before the closing of the course, the students presented their research with a fruitful debate on how their ideas could be presented to university decision-makers for consideration.

In the final discussion of the course, an overall look into the primary energy supply of the campus was further provided by the lecturer. Based on the type of energy resource that was being purchased by the university to satisfy the energy loads of the campus, the primary energy supply was calculated. In this calculation, the efficiency of about 0.34 with which electricity reaches the end users on campus, the average calorific value of natural gas at about $9.6 \mathrm{kWh} / \mathrm{m}^{3}$, the density of diesel per litre at $0.83 \mathrm{~kg} / \mathrm{litre}$, and the calorific value of diesel at $44,800 \mathrm{~kJ} / \mathrm{kg}$ were used. According to the Office of Transport 
at the university, an average of about 115,000 litres per month was stated to be used for the shuttles. As a result, including the energy consumption for the shuttles, the campus was found to have a primary energy consumption of $48 \mathrm{GWh}$. Of this total amount, 27 GWh was natural gas (heating and steam loads in buildings), $7 \mathrm{GWh}$ was electricity from the energy mix of Turkey (for lighting, laboratory equipment and cooling on campus), and $14 \mathrm{GWh}$ was diesel for transportation. The relatively higher share for natural gas in comparison to electricity for the campus is based in part on the number of buildings that have not received an insulation retrofit, which is planned.

\section{Holistic overview of the set of measures for the campus}

Table 1 gives a simplified summary of the measures that were researched by the students with their effect on reducing the natural gas, electricity, and diesel consumption of the campus. The magnitude of contribution based on the individual scenarios has been excluded from this table. The two columns on the right hand side of Table 1 further include a designation of how the measures can contribute to a net-zero exergy target for the campus if such a target was adopted. Here, measures that reduce the amount of high exergy electricity spending (e.g. LED/OLED lighting armatures) or measures that replace the direct use of high exergy natural gas for low exergy demands in buildings (e.g. poly-generation) receive a check on the column of lowering the annual exergy consumption of the campus. Likewise, another check is given to measures that increase the annual exergy production (e.g. biofuel production from the dairy farm). As a whole, this table summaries the importance of a diverse set of measures to improve the energy self-sufficiency of the campus by a more rational use of energy for energy economy. Following the course, sports equipment with dynamos have been implemented in the sports center. Not all measures, however, are as easily implemented. Currently, the greatest impact of these measures are the sense of dialogue and awareness that is created to begin considering such solutions. This was also appreciated in the university given the trends in the international arena.

Table 1. Simplified summary of measures by effect on energy economy and NZEXC target

\begin{tabular}{|c|c|c|c|c|c|}
\hline N & \multicolumn{3}{|c|}{$\begin{array}{l}\text { Effect of measure on } \\
\text { Energy Economy }\end{array}$} & \multicolumn{2}{|c|}{$\begin{array}{c}\text { NZEXC } \\
\text { target }\end{array}$} \\
\hline & 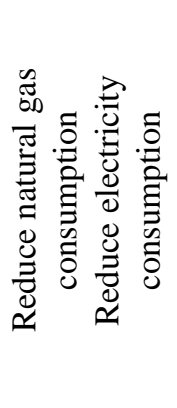 & 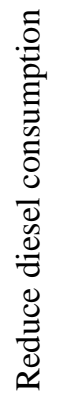 & 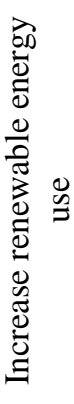 & 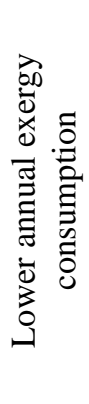 & 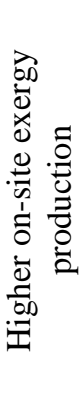 \\
\hline Electric/hybrid buses for city-campus transport & & $\checkmark$ & & $\sqrt{ }$ & \\
\hline Poly-generation for the new Concert hall and Library & $\checkmark$ & & & $\checkmark$ & \\
\hline LED/OLED lighting armatures for interior building lighting & $\checkmark$ & & & $\checkmark$ & \\
\hline PV-supported LED/OLED lighting armatures for street lighting & $\checkmark$ & & $\checkmark$ & $\checkmark$ & $\checkmark$ \\
\hline Dynamo driven equipment/piezoelectric locations on campus & $\sqrt{ }$ & & & $\checkmark$ & \\
\hline Biofuel from the university-owned dairy products farm & $\checkmark$ & $\checkmark$ & $\checkmark$ & $\checkmark$ & $\checkmark$ \\
\hline Energy management to purchase lower cost electricity at night & $\checkmark$ & & & $\checkmark$ & \\
\hline Renewable energy for an efficient technology incubation center & $\checkmark$ & & $\checkmark$ & $\checkmark$ & \\
\hline
\end{tabular}




\section{DISCUSSION OF THE RESULTS OF THE CASE STUDY}

The results of the case study provided important insights in validating the propositions for the research questions. As one of the more formal data sources, the course received the highest student evaluation of any course in the Department. The comments in the course evaluation were clustered around the uniqueness of the course and the impact of the course in opening a new perspective and intellectual horizon in the students. This may be identified with the ability of the course to trigger "epistemic learning" in the students based on a change in outlook on energy economy and perhaps a greater paradigm shift for sustainability. Such comments are interpreted to be the combined effect of the course content (lectures, discussions, workshop, and capstone research project) that diversifies the modes of skill acquisition and integrates the approach of participatory learning in multiple aspects of the course. In addition, the students commented on the benefit of the course in significantly improving their technical skills in energy economy in addition to their research skills, presentation skills, working in a team, and interacting with other team members. All of the students expressed their appreciation that the course gave them the opportunity to attain critical skills in the process of becoming an energy engineer.

These feedbacks were further validated by the direct observations of the instructor based on a total of 45 in-class hours during the semester and the documentations that were prepared by the students. Based on direct observations, the students upheld a high level of motivation during the course for learning and participation. All of the students followed the student patterns of $i$ and $i i$ with the majority of the students showing great improvement during the duration of the course. The greatest level of improvement was observed in the ability of the students to recognize opportunities to improve energy economy, logically conceptualize ideas to address these opportunities, and research their ideas. As the name suggests, this was the "capstone" aim of the course, which required the application, analysis, and synthesis of the knowledge and skills gained in the course.

The documentation was evaluated using pre-defined criteria that were coupled with an assessment of the prioritized skills. The criteria for the individual components in the capstone research projects included the ability to synthesize the knowledge and skills that are obtained in the course in a creative way and derive results from the synthesis, the method of pre-assessing the recommendation for the campus, and the research done to support the recommendation. In addition to these aspects of analytical content, the group summary required another level of synthesis to evaluate and draw linkages between the different ideas in the group. Other examples of supporting criteria includes whether an energy systems perspective and multidisciplinary views were integrated into the project.

As summarized in Figure 4, the case study is found to be successful in supporting the propositions that were put forth based on the three research questions. The integration of participatory learning approaches based on Energy Agendas, the Workshop leading to the research capstone project, and the sharing of the final project report were found to be successfully integrated into the course design (Q1). This result is based on the empirical results of the course design and the evaluation of student performance based on both direct observation and documentation. Second, the course design was able to foster skill building in such a way that students were empowered to address challenges in energy economy and find solutions for their own campus (Q2). As a whole, the design of the course increased student motivation to approach issues in energy economy with an analytical perspective wherever the problem may appear - in their classroom, their campus, their neighborhood, and even in their city and beyond.

As the aggregate result of these factors, the participatory learning approaches that were custom designed for the course increased the educational satisfaction of the students 
(Q3). Since the original writing of this paper, another semester of the course was implemented by the instructor with similar outcomes ${ }^{2}$. Again, the course received the highest evaluation in the Faculty and the comments of the students reflected a sense that epistemic learning had taken place based on a shift in outlook towards both their own skills and energy economy.

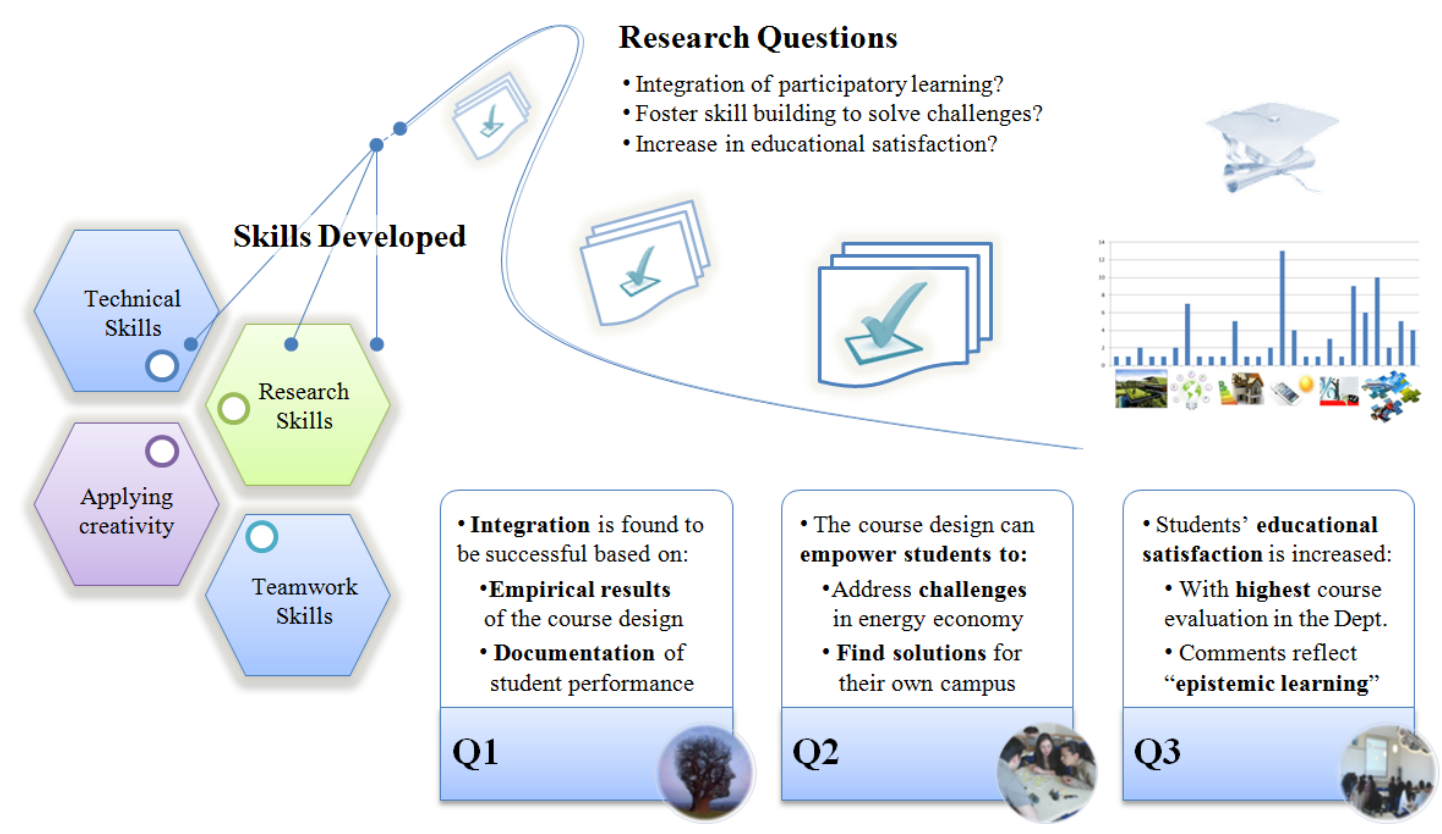

Figure 4. Summary of the results of the case study and research design

\section{Comparison of the capstone project with international examples}

The Workshop and capstone project for the campus application were among the novel aspects of the course, with the only similar initiative being a student-led Energy Initiative at TU Delft University of Technology in the Netherlands [41]. In the Delft Energy Initiative, the campus targets a 30\% energy savings in 2020 relative to 2009 values and at least a $50 \%$ and preferably a $100 \%$ renewable energy usage on campus. In addition, the campus aims to have "carbon neutrality" considering the energy sources that are used to satisfy the energy loads of the campus [42]. According to their "Energy Monitor," the campus was found to consume as much energy as a district with a population of 11,000 people.

In total, the TU Delft campus was given to have a total area of $450,000 \mathrm{~m}^{2}$ and energy loads of $73 \mathrm{GWh}$ for electricity and $70 \mathrm{GWh}$ for heating in 2010. The natural gas consumption is given to be $2.6 \mathrm{GWh}$ and the total primary energy consumption is given to be $273 \mathrm{GWh}$, which indicates that electricity is also used to satisfy the heating loads of the campus. Although a majority of students in TU Delft use bicycles for transport, vehicle related energy consumption is not included in the Energy Monitor. A competition called "The Game" was also opened on campus by the student-led group to produce new ideas for energy solutions, such as wind turbines with unique design on campus, the usage of waste heat from laboratory equipment based on thermo-electric modules, the use of geothermal heat and solar energy on campus, and the usage of electric vehicles [43].

\footnotetext{
${ }^{2}$ The first course in Energy Economy (the case study) was given in Spring Semester 2012. The second version of the course was given in Fall 2013. The second version implemented the same framework with time-bound updates in content. In addition, it added a multi-criteria technology ranking index following the "Technology Summaries" and a questionnaire prior to the Workshop to assess student perception.
} 
Such activities were not integrated with more detailed research studies in the academic curriculum.

In contrast, the first-of-its-kind course in "Energy Economy" that was designed and applied at Başkent University in Turkey represents a case study of how educational objectives may be integrated with the sustainability goals for a campus. It is also possible to give other examples of energy projects at universities that are not integrated with the academic curriculum, such as the "net-zero energy" West Student Dormitory Village at the University of California, Davis [44]. Such opportunities forgo the possibility of benefiting from student creativity and making the linkage between academic studies and societal needs. On the other hand, Massachusetts Institute of Technology offers a course in "Energy Economics" that is given by the Economics Department [45]. This course has limited coverage of topics that are necessary for the type of analysis that need to be conducted by "energy engineers" and does not provide an integrated view of the energy system. The best practises of the case study may provide alternative perspectives on how courses in energy economy could be designed for sustainability.

The lessons of the course could also provide insight to the National University of Singapore, which has recently put a target to increase the use of the participatory method to stimulate and motivate students [21]. Other signatories of ISCN that have sustainability initiatives include the KTH Royal Institute of Technology in Sweden. KTH has initiated a research cluster on "Urban Sustainability" that seeks to provide a common platform for about 100 researchers from various disciplines [46]. However, the platform functions more as a researcher-to-researcher network rather than a platform to exchange pedagogical experiences and increase participatory methods in the academic curriculum to mobilize student participation for sustainability in and outside of campus. Other universities who would like to start sustainable campus initiatives can benefit from their student's ideas with curriculum based applied projects.

In addition to a project-based, participatory nature of the course, a strong interdisciplinary aspect is necessary. An overview of financial incentives and credits for energy savings and renewable energy technology, innovation systems, and learning rates must be provided to complement technical knowledge with policy-relevant knowledge. Often, engineering students are not introduced to concepts that impact the very technologies with which they work on a daily basis, such as technological progress and technological trends. As a way of keeping engineers up to date on recent developments, they should also be encouraged to work with innovative concepts, such as net-zero targets, as was done in this course. In the course, two lectures were also dedicated to the Rational Exergy Management Model and net-zero exergy buildings [34]. The high course evaluations indicate that the novel features of the course were well-received by the student sample to be considered as a best practise.

\section{CONCLUSION: BEST PRACTISES OF THE COURSE}

The present research contributes to different streams of studies in the literature with a unique case study. Based on the results of the research capstone project, it contributes to studies on campus sustainability initiatives (e.g. Refs. [11-15]). Based on the course design and its implementation, it contributes to the literature on participatory approaches (e.g. Refs. [27-31]). As a whole, the research design validates the main proposition that a novel course in Energy Economy can integrate participatory learning approaches while presenting the campus as an "open laboratory" for energy solutions. This provides a basis to recommend that the academic curriculum, especially in energy engineering and other disciplines with a direct linkage to sustainability, is better integrated with campus greening initiatives. 
Based on multiple data sources, including direct observations, documentations, and student observations, the course in "Energy Economy" is found to successfully integrate pedagogical approaches for skill attainment towards the aim of educating energy engineers. The sample of students in the course are found to have gained a working knowledge of an energy systems perspective and strong research skills to produce solutions for their common living and working space - their own campus. An energy systems perspective within energy economy is especially important in being able to propose solutions that maximize savings in primary energy and $\mathrm{CO}_{2}$ emissions while having reasonable payback periods. The pedagogical features of the course demonstrate how renewal of the course content can be coupled with the aim of engaging students in creative modes of learning and applied research, including towards a more self-sufficient, net-zero exergy campus [38].

The pedagogical features of the case study were built upon a toolkit for gaining an energy systems perspective, developing collective effort in energy agendas, engaging in a thematic, collaborative workshop, and researching a capstone project dedicated to campus applications. By novel design of the course, the skills that were fostered by these pedagogical features made an integrated whole since the toolkit for an energy systems perspective were directly used in analyzing the measures for the campus application project. The team-building and leadership skills that were encouraged in the Energy Agendas were a good basis for using similar skills in the campus projects within the 5 teams. The workshop that was used as a brainstorming and pre-evaluation session for the campus project was also a novel component of the course, which engaged students in lively discussions. Finally, the capstone research project allowed the students to produce knowledge that could be of benefit for the future of their university, thus bringing them closer to being "energy engineers" who can "engineer" solutions in society for a more sustainable energy future.

It is envisioned that the dissemination of the best practises of the course will be of value to other courses in energy economy around the world. As overviewed in the paper, these may include National University of Singapore, Delft University of Technology, and KTH Royal Institute of Technology. It may also include signatories of the (ISCN) Gulf Charter to better integrate the academic curriculum, especially based on participatory approaches, with green campus initiatives. Each educator is responsible for engaging their students in realizing their full power to contribute to sustainable development. The prospect of integrating the academic curriculum with the objective of positioning the campus as an "open laboratory" for energy solutions presents a valuable opportunity that is not to be missed.

\section{ACKNOWELEDGMENTS}

The author would like to extend a sincere and special appreciation to the students who enthusiastically participated in the course and provided the initial foundation to offer additional sections of the course in the future. The lecturer also gives thanks to the Graduate Program in Energy Engineering at Başkent University for allowing a redesign of the course. The paper has been developed from an original manuscript that was presented at the $8^{\text {th }}$ Conference on SDEWES in Dubrovnik, Croatia during September 22-27, 2013. The reviewers are kindly acknowledged for their valuable suggestions.

\section{REFERENCES}

1. Chen, K., Huang, S., Liu, S., Devising a Framework For Energy Education In Taiwan Using the Analytic Hierarchy Process, Energy Policy, Vol. 55, pp 396-403, 2013, http://dx.doi.org/10.1016/j.enpol.2012.12.025 
2. DeWaters, J., Powers, S., Graham, M., Developing an Energy Literacy Scale, $114^{\text {th }}$ Annual ASEE Conference and Exposition, Honolulu, 2011.

3. Kandpal, T. C., Garg, H., Energy Education, Applied Energy, Vol. 64, No. 1-4, pp 71-78, 1999, http://dx.doi.org/10.1016/S0306-2619(99)00076-8

4. Desha, C., Hargroves, K., Informing Engineering Education for Sustainable Development Using a Deliberative Dynamic Model for Curriculum Renewal, Proc. of the Research in Engineering Education Symposium 2011, Madrid, 2011.

5. Desha, C., Hargroves, K., Smith, M., Addressing the Time Lag Dilemma in Curriculum Renewal Towards Engineering Education for Sustainable Development, Int. Journal of Sustainability in Higher Education, Vol. 10, No. 2, pp 184-199, 2009, http://dx.doi.org/10.1108/14676370910949356

6. Desha, C., Hargroves, K., Surveying the State of Higher Education in Energy Efficiency, in Australian Engineering Curriculum, International Journal of Cleaner Production, Vol. 18, No. 7, pp 652-658, 2010, http://dx.doi.org/10.1016/j.jclepro.2009.07.004

7. Mulder, K., Desha, C., Hargroves, K. C., Sustainable Development as a Meta-Context for Engineering Education, Journal of Sustainable Development of Energy, Water and Environment Systems, Vol. 1, No. 4, pp 304-310, 2013, http://dx.doi.org/10.13044/j.sdewes.2013.01.0023

8. Youtie, J., Shapira, P., Building an Innovation Hub: A Case Study of the Transformation of University Roles in Regional Technological and Economic Development, Research Policy, Vol. 37, No. 8, pp 1188-1204, 2008, http://dx.doi.org/10.1016/j.respol.2008.04.012

9. Sedlacek, S., The Role of Universities in Fostering Sustainable Development at the Regional Level, Journal of Cleaner Production, Vol. 48, pp 74-84, 2013, http://dx.doi.org/10.1016/j.jclepro.2013.01.029

10. Peer, V., Stoeglehner, G., Universities as Change Agents for Sustainability - Framing the Role of Knowledge Transfer and Generation in Regional Development Processes, Journal of Cleaner Production, Vol. 44, pp 85-95, 2013, http://dx.doi.org/10.1016/j.jclepro.2012.12.003

11. Yıldırım, N., Toksoy, M., Gökçen, G., District Heating System Design for a University Campus, Energy and Buildings, Vol. 38, No. 9, pp 1111-1119, 2006, http://dx.doi.org/10.1016/j.enbuild.2006.01.004

12. Pagliarini, G., Rainieri, S., Modeling of a Thermal Energy Storage System Coupled with Combined Heat and Power Generation for the Heating Requirements of a University Campus, Applied Thermal Engineering, Vol. 30, No. 10, pp 1255-1261, 2010, http://dx.doi.org/10.1016/j.applthermaleng.2010.02.008

13. Shang, J., Pollet, B., Hydrogen Fuel Cell Hybrid Scooter (HFCHS) with Plug-In Features on Birmingham Campus, International Journal of Hydrogen Energy, Vol. 35, No. 23, pp 12709-12715, 2010, http://dx.doi.org/10.1016/j.ijhydene.2010.08.075

14. Spencer, J., Moton, J., Gibbons, W., Gluesenkamp, K., Ahmed, I., et al., Design of a Combined Heat, Hydrogen, and Power Plant from University Campus Waste Streams, International Journal of Hydrogen Energy, Vol. 35, No. 12, pp 4889-4900, 2013, http://dx.doi.org/10.1016/j.ijhydene.2013.02.021

15. Spirovski, D., Abazi, A., Iljazi, I., Ismaili, M., Cassulo, G., Venturin, A., Realization of a Low Emission University Campus through the Implementation of a Climate Action Plan, Procedia - Social and Behavioral Sciences, Vol. 46, pp 4695-4702, 2012, http://dx.doi.org/10.1016/j.sbspro.2012.06.321

16. Lo, K., Energy Conservation in China's Higher Education Institutions, Energy Policy, Vol. 56, pp 703-710, 2013. 
17. Zografakis, N., Menegaki, A., Tsagarakis, K., Effective Education for Energy Efficiency, Energy Policy, Vol. 36, No. 8, pp 3226-3232, 2008, http://dx.doi.org/10.1016/j.enpol.2008.04.021

18. International Sustainable Campus Network, ISCN/Gulf Sustainable Campus Charter, http://www.international-sustainable-campus-network.org/, [Accessed: 19-May-2014]

19. Lappeenranta University, ISCN Conference 2013, Singapore, http://www. international-sustainable-campus-network.org/2013-conference/2013-iscn-conference. html, [Accessed: 19-May-2014]

20. Barazzone, E., Whitney, M., Hassenzahl, D., Chatham University, ISCN Conference 2013, Singapore, http://www.international-sustainable-campus- network.org/2013conference/2013-iscn-conference.html

21. National University Singapore ISCN - Gulf Charter Report, March 2011.

22. Energy Engineering Graduate Program, Başkent University, Faculty of Science, Literature and Engineering, Ankara, www.baskent.edu.tr, [Accessed: 19-May-2014]

23. Merriam-Webster's Learners Dictionary, http://www.learnersdictionary.com

24. Bloom, B.S. Ed., Taxonomy of Educational Objectives: The Classification of Educational Goals, Handbook 1: Cognitive Domain, Longman, New York, 1956.

25. Rehage, K., Anderson, L., Sosniak, L., Bloom's Taxonomy: A Forty-Year Retrospective, National Society for the Study of Education Yearbook, Chicago, 1994.

26. Marzano, R., Kendall, J., Eds., The New Taxonomy of Educational Objectives, Corwin Press, Thousand Oaks, California, 2007.

27. Bielefeldt, A., Pedagogies to Achieve Sustainability Learning Outcomes in Civil and Environmental Engineering Students, Sustainability, Vol. 5, pp 4479-4501, 2013, http://dx.doi.org/10.3390/su5104479

28. Jollands, M., Parthasarathy, R., Developing Engineering Students' Understanding of Sustainability Using Project Based Learning, Sustainability, Vol. 5, No. 12, pp 5052-66, 2013, http://dx.doi.org/10.3390/su5125052

29. Sterling, S. Transformative Learning and Sustainability: Sketching the Conceptual Ground, Learning and Teaching in Higher Education, Vol. 5, pp 17-33, 2011.

30. Blake, J., Sterling, S., Goodson, I., Transformative Learning for a Sustainable Future: An Exploration of Pedagogies for Change at an Alternative College, Sustainability, Vol. 5, No. 12, pp 5347-5372, 2013, http://dx.doi.org/10.3390/su5125347

31. Disterheft, A., Caeiroa, S., Azeiteiroa, U., Filho, W., Sustainable Universities - A Study of Critical Success Factors for Participatory Approaches, Journal of Cleaner Production, (In Press), pp 1-11, 2014, http://dx.doi.org/10.1016/j.jclepro.2014.01.030

32. Decade of Education for Sustainable Development, http://www.desd.org/, [Accessed: 19-May-2014]

33. Yin, R., Case Study Research: Design and Methods 5th Edition, SAGE Publ. Inc., Thousand Oaks, California, 2014.

34. Kılkış, Ş., A Rational Exergy Management Model to Curb $\mathrm{CO}_{2}$ Emissions in the Exergy-Aware Built Environments of the Future, PhD Thesis, KTH Royal Institute of Technology School of Architecture and the Built Environment, Stockholm, 2011.

35. Directive 2012/27/EU of the European Parliament and of the Council of 25 October 2012 on Energy Efficiency, L 315, Vol. 55, 14 November 2012.

36. Directive on the Energy Performance of Buildings (Binalarda Enerji Performans Yönetmeliği), Official Gazette No. 27075 on 5 December 2008.

37. Neij, L., Cost Development of Future Technologies for Power Generation - A Study Based on Experience Curves and Complementary Bottom-up Assessments, Energy Policy, Vol. 36, No. 6, pp 2200-2211, 2008, http://dx.doi.org/10.1016/j.enpol.2008.02.029

38. Kılkış, Ş., Energy Economy ENE 523 Lecture Notes, Başkent University, 2012. 
39. General Directorate of Meteorology, Heating and Cooling Degree Days, http://www.mgm.gov.tr/veridegerlendirme/gun-derece.aspx,

[Accessed: 19-May-2014]

40. Harrop, P., Das, R., Energy Harvesting and Storage for Electronic Devices 2012-2022: Forecasts, Technologies Players, http://www.idtechex.com/research/re ports/ energy-harvesting-and-storage-for-electronic-devices-2012-2022-000316.asp, [Accessed: 19-May-2014]

41. Wijk, A., Hellinga, C., Towards the Green Campus at TU Delft, Delft, November 2011.

42. TU Delft, TU Delft Energy Monitor, http://www.tudelft.nl/en/research/energy/ energyon-the-campus/energy-monitor, [Accessed: 19-May-2014]

43. Delft Energy Initiative, The Game, http://energyclub.nl/thegame, [Accessed: 19-May-2014]

44. Department of Energy, Office of Efficiency and Renewable Energy CRED Webinar, UC Davis West Village "Zero Net Energy" Community, http://www1.eere.energy.gov /office_eere/pdfs/webinar_ucdavid_west_village.pdf, [Accessed: 19-May-2014]

45. Massachusetts Institute of Technology, MIT Open Courseware, Energy Economy, http://ocw.mit.edu/courses/economics/14-44-energy-economics-spring-2007, [Accessed: 19-May-2014]

46. The KTH Royal Institute of Technology, Research Cluster for Urban Sustainability, http://www.kth.se/en/abe/2.28505, [Accessed: 19-May-2014] 